\title{
Competency Model Development for Job Creation for Undergraduate Students: Focusing on Undergraduate Students Preparing for Franchise Job Creation
}

\author{
Hyun-Kyung PARK ${ }^{1}$, Sang Seub LEE ${ }^{2}$
}

Received: August 05, 2020. Revised: August 15, 2020. Accepted: August 30, 2020.

\begin{abstract}
Purpose: This study was conducted for purpose to derive a model of the founding competency of undergraduate students preparing for job creation. We want to support undergraduate students who are preparing to start a job creation so that they can successfully start a job creation. In Korea, research on entrepreneurship competency has been actively conducted for a variety of subjects including undergraduate students, but research on job creation competency is insufficient. To this end, we intend to contribute to the success of undergraduate students preparing for job creation by deriving a job competency model. Research design, data, and methodology: In order to derive job creation competency, interviews were conducted with best practices in the job creation activity process, and the job creation competency was derived using Spencer and Spencer's competency model development process and competency dictionary. Result: The derived competencies were further supplemented through the verification of job creation experts and HRD experts, and a total of 3 competency groups, 13 competences, and 44 specific actions were derived. The derived job creation competency model is significant in that it is an initial study that attempts to develop job creation competency, that it can be a reference point for developing curriculum for undergraduate students preparing for job creation, and that they have developed a competency model in the new field of job creation. However, despite this significance, there are some limitations. First, the derived competency model did not perform validity verification using quantitative research. Second, the difference analysis between the excellent group and the average group was not conducted. Third, the level of behaviors could not be staged. Lastly, it was not possible to compare it with the competency of franchisor and job creation for undergraduate student competency. Therefore, it is necessary to upgrade the job creation competency model by conducting follow-up studies. The following is suggested as a follow-up study. First, verification of the validity of job creation competency, and second, a comparative study of excellent cases and average group. Third, a study on the level of action level of job creation competency. Lastly, it is a comparative study of job creation competency and the competency of franchise affiliates.
\end{abstract}

Keywords: Job Creation Competency, Job Creation, Job Creation Activity, Competency

JEL Classification Code: M12, M13, M19.

\section{1. 서론}

1 First Author, Doctoral Student, Dept. of Education Consulting, Dongduk Women's University, South Korea. Tel: +82-2-919-7564, Email: 0425phk@gmail.com

2 Corresponding Author, Associate Professor, Dept. of Education Consulting, Dongduk Women's University, South Korea.

Tel: +82-2-940-4697, Email: sangseub@dongduk.ac.kr

(c) Copyright: The Author(s)

This is an Open Access article distributed under the terms of the Creative Commons Attribution Non-Commercial License (https://creativecommons.org/licenses/by-nc/4.0/) which permits unrestricted non-commercial use, distribution, and reproduction in any medium, provided the original work is properly cited.

\begin{abstract}
자고 일어나면 세상이 순식간에 바뀌었다는 말이 무색할 정도로 오늘날 기술의 발전은 상상 이상으로 빠르게 변화하고 있다. 이에 따라, 산업구조 또한 소수 인력이 고비용을 창출할 수 있는 구조가 정착되고 있으며, 그 결과 '고용 없는 성장'의 경제구조가 형성되고 있다. 이러한 경제구조는 결국 경제 인구의 불안정한 일자리를
\end{abstract}


증대시키는데 일조하였고, 젊은 세대들은 삼포세대부터 육포세대라는 다양한 신조어까지 만들며 현재의 일자리 상황을 비판하고 있다. 2019 년 7 월 통계청에서 배포된 '2019 년 5 월 경제활동인구조사 청년층 부가조사 결과'에 따르면, 2010 년 5 월과 2019 년 5 월의 청년층 경제활동 상태를 비교했을 때, 경제활동인구는 4,368,000 명에서 4,390,000 명으로 증가되었다 (KOSTAT, 2019). 그러나, 비경제활동 청년층의 취업시험 준비자 비율은 전년 동월대비 $2.2 \%$ 상승하였으며, 취업준비분야는 $30.7 \%$ 가 일반직공무원을, 기능분야 자격증 및 기타가 $24.8 \%$, 일반기업체 23.7\% (KOSTAT, 2019)로 비경제활동 청년층이 다양한 직무 또는 직업을 구직하는 것이 아닌, 정년이 보장되고 안정적인 직장을 구직하고 있음을 알 수 있었다.

고용불안정, 취업난 등을 타개하기 위해 정부는 창업진흥정책을 내세우며, 기존의 일자리에만 얽매이는 것이 아닌, 새로운 일자리를 창출하고 새로운 기업 생성을 통해 고용까지 창출하기 위한 지원을 아끼지 않고 있다. 즉, 정부는 1 인 기업, 중소, 벤처 기업들의 부흥을 지원하여 신규 일자리 창출 실업 및 특정 직업으로 쏠리는 현상을 극복하고자 하는 것이다.

이러한 흐름에 힘입어 고용시장에서는 기존에 존재하지 않았던 직업을 창조하고 이를 통해 새로운 일자리를 만드는 '창직'이라는 개념이 등장하게 되었다 (Kim, Lee, Lee, \& Lee, 2011). 창직이란 "자신의 아이디어나 재능, 활동을 통하여 새로운 가치를 창출함으로써 스스로 새로운 직업을 개발·발굴하고, 신규 일자리를 창출하는 활동"이라고 정의된다 (Lee, Koo, \& Hwang, 2010). 새로운 직업을 창출하는 창직활동을 활성화시키기 위하여 고용노동부와 한국산업인력공단이 주관하고 $\mathrm{A}$ 기관, $\mathrm{B}$ 기관, $\mathrm{C}$ 기관 등의 운영기관에서 청년취업아카데미 창직과정을 운영되고 있다. 청년취업아카데미 창직과정은 매년 약 800 명의 대학생을 대상으로 실시되며, 각 운영기관에서 선발된 우수팀을 모아 우수팀의 창직 아이디어를 평가하는 창직어워드를 매년 실시하고 있다. 그러나, 매년 창직과정을 진행하여 신규직업을 배출하는 것이 실업률 해소와 고용창출을 독려하기 위한 방안 중 하나임을 인지하고 있음에도 불구하고, 창직에 대한 연구는 부족한 상황이며, 특히 창직을 준비하는 대상이 갖춰야 할 역량에 대한 연구는 미비한 실정이다. 이에, 본 연구에서는 창직을 준비하는 대학생 역량을 도출하기 위하여, 창직과정 우수 사례자 분석을 실시하였다. 또한, 우수자들이 공통적으로 갖추고 있는 역량을 도출함으로써 창직을 준비하는 대상자들이 갖춰야 할 역량을 제시하고, 직업으로써의 가치를 정착시키기 위한 작업에 일조하고자 한다. 나아가 안정된 직업으로 정착한 후 확장을 통해 가맹사업으로 나아갈 수 있는 기반을 제공하고자 한다. 이에 따라 본 연구에서는 다음과 같은 연구문제를 제시하였다.
$\mathrm{RQ1}$ : 창직을 준비하는 대학생의 필요 역량요소는 무엇인가?

RQ2: 도출된 창직역량과 프랜차이즈 가맹사업자의 역량 비교를 통해 공통된 역량을 발견할 수 있는가?

\section{2. 이론적 고찰}

\section{1. 창직 개념 및 특성에 대한 연구}

\subsection{1. 창직의 정의}

창직의 개념은 2009 년 7 월 26 일 매경이코노미 "1 인 창직시대 '두드리면 열린다' - 이전에 없던 직종 만들어 1 인 기업가가 되라"라는 기사에서 최초로 언급되었다 (Kim, Choi, \& Choi, 2016; Kim, Kim \& Choi, 2015; Kim, Lee, \& Kwon, 2014; Kim, Lee, Lee, \& Lee, 2011).

Lee, Koo, and Hwang (2010)는 '창직 (창조적 직업능력계발)은 자신의 재능과 아이디어를 적극적으로 현실화하여 경제적, 예술적, 사회적 가치를 창출해 냄으로써 창조적 일감과 일자리를 만들어나가고 자기 주도적으로 직업과 일자리를 개척하는 활동'이라는 광의의 개념과 '새로운 경제 패러다임 (창조경제)과 사회적 네트워크를 적극 활용해 스스로 일자리를 만들고 자기 자신을 고용하는 창조적 활동'이라는 정책적 정의로 나누어 정의하였다. 이에 창직은 創 (비롯할 창), 職 (직분 직)을 '새로운 직업을 처음으로 만들어 시작하거나 만족한 일자리를 스스로 마련함으로써 행복을 추구하려는 트렌드'로 정의했다는 점에서 의의가 있으나, 창직에 대한 개념 정립을 문화 콘텐츠 산업분야로 제한하고 있다는 한계도 있다 (Kim, Lee, Oh, \& Lee, 2013).

Kim et al. (2011)은 콘텐츠 산업분야 뿐만 아니라 다양한 산업분야를 포괄한 의미의 창직 개념이 필요하며, 창직활동의 목적 및 결과에 대한 다양성이 인정될 수 있는 개념이 필요하다고 주장하였다. 이러한 주장에 따라 창직, 창직 활동, 창직역량으로 나누어 의미를 정의하였다. Table 1 은 Kim et al. (2011)가 정의한 창직, 창직 활동, 창직역량에 대한 정의이다.

Table 1 과 같이 Kim et al. (2011)은 창직을 창직, 창직활동, 창직역량으로 세분화하여 정의하였으며, 이 중 창직역량은 "창직활동 체험자가 창직활동을 통하여 얻어질 수 있는 다양한 직무관련 능력"이라 정의하였다. Kim et al. (2015)은 창직을 '새로운 직업 (또는 일자리)을 만드는 것'이라고 정의하였으며, 창직이 신직업 연구와 차이점은 정부 또는 공공기관에서 실시하는 신직업 연구 및 육성지원 활동은 국민의 일자리 창출이나 개인의 
진로선택을 지원하기 위한 정보 개발에 목표를 두고 있다면, 창직은 개인의 창의적 아이디어와 지식, 경험, 네트워크 등을 활용하여 자신의 일자리를 만드는 개별활동으로 창직과 신직업 연구가 구분된다고 주장하였다.

Table 1: Definition of Job Creation

\begin{tabular}{|c|c|}
\hline Concept & Definition \\
\hline Job Creation & $\begin{array}{c}\text { Developing new jobs and self-directed job } \\
\text { creation. As specific achievements, new } \\
\text { occupations, employment, entrepreneurship, and } \\
\text { social contribution activities can be suggested. }\end{array}$ \\
\hline $\begin{array}{c}\text { Job Creation } \\
\text { Activity }\end{array}$ & $\begin{array}{c}\text { Various capacity-building experience activities to } \\
\text { realize job creation }\end{array}$ \\
\hline $\begin{array}{c}\text { Job Creation } \\
\text { Competency }\end{array}$ & $\begin{array}{r}\text { Various job-related skills that can be obtained } \\
\text { through job-seeking experience }\end{array}$ \\
\hline
\end{tabular}

앞선 Kim et al. (2011)가 주장했던 창직과 창직활동의 개념 분리와 달리 Kim, Kim, and Choi (2015)는 직업을 만드는 것과 직업을 만드는 과정에서 학습한 지식, 기술, 경험 등의 역량은 사회생활 시 중요하게 작용하므로 창직활동과 창직이 함께 사용되어야 함도 언급하였으며, "개인이 기존 노동시장의 일자리에 진입하지 않고 문화, 예술, $\Pi$, 농업, 제조업 등 다양한 분야에서 변화하는 직업세계를 토대로 창의적인 아이디어와 활동을 통해 자신의 지식, 기술, 능력, 흥미, 적성 등을 활용하여 직업 (또는 아이디어)을 발굴하여 본인의 진로로 삼으며 이를 통해 일자리를 창출하는 것"으로 창직을 정의하였다.

즉, 창직의 개념은 처음 문화 콘텐츠 산업으로 한정되어 시작되었으나, 추후 연구자들의 내용을 반영하여 점차 그 의미가 확대되었음을 알 수 있다. 따라서, 선행 연구를 바탕으로 본 연구에서는 창직이란 "기존 노동시장에 배치된 직업에서 벗어나, 개인의 지식, 기술, 능력, 흥미, 인적 네트워크, 적성과 사회적 변화를 융합하여 스스로 직업을 개발하고 직업적 요소를 갖춰 일자리를 만드는 행위"라고 정의한다.

\subsection{2. 창직의 조건}

창직에 해당하려면 다음과 같이 참신성, 경제성, 현실성 3 가지 조건을 갖춰야 하며, 상황에 따라 기타 조건도 부합해야 한다 (Kim et al., 2015; 2014; 2013). 창직의 조건에 대한 세부 내용은 Table 2 와 같다.

창직은 기존에 존재하지 않거나 기존 직업에서 행했던 지식, 스킬, 능력, 작업 활동이 달라야 하며 (참신성), 직업으로서 지속 가능성을 갖추고 잠재적 시장수요가 충분해야 하며 (경제성), 실제 시장에서 실현 가능성이 (현실성) 있어야 한다.
Table 2: Condition of Job Creation

\begin{tabular}{|c|c|}
\hline $\begin{array}{l}\text { Condition } \\
\text { of } \\
\text { Job Creation }\end{array}$ & Detailed Contents \\
\hline \multirow{3}{*}{ Originality } & Must be a job that didn't exist before \\
\hline & $\begin{array}{l}\text { Knowledge, skills, abilities, job activities, etc. } \\
\text { must be different from existing jobs }\end{array}$ \\
\hline & $\begin{array}{c}\text { This includes not only all new jobs, but also } \\
\text { convergence between existing jobs or } \\
\text { differentiation in existing jobs }\end{array}$ \\
\hline $\begin{array}{l}\text { Economic } \\
\text { feasibility }\end{array}$ & $\begin{array}{l}\text { As a job, there must be sufficient } \\
\text { competitiveness and potential market demands } \\
\text { for sustainability. }\end{array}$ \\
\hline Feasibility & Must be feasible in the market \\
\hline \multirow{2}{*}{ Other } & $\begin{array}{l}\text { It must be a job that requires expertise, and if } \\
\text { the market demand increases, it can lead to } \\
\text { start-up. }\end{array}$ \\
\hline & $\begin{array}{l}\text { New jobs creation abilities allow you to work in } \\
\text { a business in recognition of your creation ability }\end{array}$ \\
\hline
\end{tabular}

\subsection{3. 창직 관련 선행연구}

대학생 창직역량에 대한 연구에 앞서, 창직과 관련된 국내 선행연구를 검토하였다. 검색 도구는 학술연구정보서비스 (RISS)를 사용했으며, 검색어로는 '창직', '창직역량', '창직교육', '창직동기', '창직의도' 등 창직과 관련된 연관 검색어를 사용하였다. 창직과 관련된 선행연구는 다음과 같다.

$\operatorname{Lim}$ (2016)는 사회적자본이 창직동기 및 창직의도에 미치는 영향 연구에서 창직경험이 있는 또는 창직교육을 수강한 교육생을 대상으로 설문을 실시하였다. 그 결과 사회적 자본의 요소 중 다양한 활동을 참여하는 '활동요소'는 창직동기에 유의미한 영향을 미치며, 창직동기와 창직의도는 밀접한 관계가 있음을 결과로 도출하였다.

Yi (2017)은 창직 성공 경험에 대한 내러티브 연구를 통하여 연구대상자들이 전문성과 경력을 활용할 수 있는 아이템을 찾아 창직에 도전하여 성공적인 안착을 했음을 연구결과로 도출하였다. 또한, 차별화된 아이템과 적극적으로 트렌드를 반영하는 태도, 자신감 등이 창직 성공자에게 나타났음을 연구결과로 제시하였다.

Yoon and Kim (2019)은 어떤 요인들이 대학생의 창직의도에 유의미한 영향을 미치는지 연구를 진행하였다. 그 결과 대학생의 기업가 열정의 3 요소인 발명, 설립, 성장이 탐색활동에 유의미한 영향을 주며, 아이디어 발굴 및 새로운 정보 발굴 등의 탐색활동은 창직의도에 유의미한 영향을 준다는 결과를 도출하였다.

Shin (2019)은 셀프리더십이 창직/프리랜서직 종사자의 직무만족에 미치는 영향 연구를 수행하였으며, 셀프리더십이 창직/프리랜서직 종사자의 직무만족에 긍정적 영향을 미침을 
결과로 도출하고, 이를 바탕으로 전직 (Outplacement)을 희망하는 대상 중 창직/프리랜서직을 희망하는 종사자에게 셀프리더십을 향상시키는 교육을 제공해야 함을 주장하였다.

앞선 선행연구를 살펴보면, 창직교육 및 창직활동이 현재까지 진행되고 있음에도 불구하고 창직과 관련된 연구자료는 국내에서 손에 꼽힐 정도로 소수임을 알 수 있었다. 또한, 성공적으로 창직을 수행하기 위한 역량분석은 아직까지 연구가 미비하였다. 이에 따라 창직역량에 대한 선행연구의 범위를 확장하여, 본 연구 대상인 대학생의 역량개발과 관련한 연구도 선행연구의 범위에 포함 시켜 진행하였다.

\subsection{4. 창직과 창업의 차이}

KOSTAT (2008)에서 제작한 한국표준직업분류 이용 지침서에 따르면, 직업이란 '유사한 직무의 집합'으로 정의하고 있으며, 직무는 '자영업을 포함하여 특정한 고용주를 위해 개별 종사자들이 수행하거나 또는 수행해야 할 일련의 업무와 과업'이라 정의하고 있다. 직업이 되기 위한 조건으로는 유사성을 갖은 직무들을 계속해서 수행해야 하며, 경제적인 거래 관계가 성립하여 경제성이 충족되어야 하고, 윤리성과 사회성을 충족시키는 것을 직업이라고 정의하고 있다. 때문에, 일부에서는 창직과 창업에 대해 동일한 뜻으로 인식하는 경우가 많다.

Kim et al. (2015)은 창직과 창업의 차이를 명확히 나누고 있으며, 창업 아이템 중에서 기존의 것과 다른 새로운 것을 만들어냈다면 창직 혹은 창직활동으로 볼 수 있다고 설명하고 있다. 또한, 창직과 창업은 추구하는 지향점에서도 차이가 있다. 창직자는 제품과 서비스뿐만 아니라 양질의 인력을 양성하는 교육훈련 프로그램 개발, 자격제도 개발 및 보급도 창직 활동의 영역이라 할 수 있으나, 창업은 제공하는 제품 및 서비스의 내용 및 품질이 소비자의 기대에 부응할 수 있는지에 중점을 두고 있다 (Kim et al., 2015). 따라서 창업으로 제공되는 제품이나 서비스는 트렌드에 따라 생성되거나 사라질 수 있다는 특징을 지니고 있다. 즉 창직 또는 창직활동의 결과물이 창업활동, 프리랜서, 취업 등의 형태로 나타나는 것이며, 창업은 창직의 결과물로 포함되는 하나의 형태라고 말할 수 있다 (Kim et al., 2015; 2014; 2013).

\section{2. 역량에 대한 연구}

\subsection{1. 역량의 개념}

사전적 의미로 '어떤 일을 해낼 수 있는 힘'이라는 뜻을 지닌 역량은 보통 Competency 또는 Competence 를 혼용하여 사용하지만, 인력과 조직 관리 학문 분야에서는 두 단어가
구분되어 사용된다 (Lee, 2016; Park \& Kim, 2004). Competence 는 조직역량으로써 어떤 조직이 다른 조직과 비교했을 때 우수한 성과를 내는 원인이 조직에 있다고 판단할 때 사용하며, Competency 는 조직이 우수한 성과를 창출하는 원인을 개인의 역량에 있다고 판단하는 개인역량에 사용한다 (Lee, 2016).

경제학자인 1911 년 Frederick Taylor 가 노동자의 업무 표준화를 제정하며 최초로 언급했던 '역량'은, McClelland (1973)에 의해 현재 우리가 사용하는 개념으로 정착하게 되었다. McClelland (1973)는 역량의 속성은 지식, 기술, 태도, 가치, 동기 등 개인이 가지고 있으며 육안으로 관찰되지 않지만 지속적으로 행동에 영향을 미치는 요소라 정의하였다.

Spencer and Spencer (1993)는 개인이 보유한 역량이 어느 정도 수준으로 개발되었는지에 따라 동기, 특성, 자아개념, 기술, 지식으로 역량의 단계를 구분하였다. 또한 역량을 내면에 있는 역량 (동기, 특성, 자아개념)과 관찰 가능한 역량 (기술, 지식)으로 구분하였다. Spencer and Spencer (1993)가 구분한 역량의 단계 중 '동기'는, 개인이 원하는 목표를 이루기 위한 촉진제의 역할을 수행하며, '자아개념'은 태도, 가치관 또는 자기상을, '지식'은 특정 분야에 대한 정보 또는 정보를 발견할 수 있는 능력으로, '기술'은 과업을 수행할 수 있는 특정 능력이라고 정의하였다.

McLagan (1989)은 직무 및 역할 수행에 우수한 성과를 창출하는 성과자가 갖고 있는 개인적 특성을 역량으로 정의하였으며, Parry (1996)는 개인의 업무에 중요한 영향을 주며, 업무성과와 높은 관련성을 갖고 있고, 조직의 성과 기준에 대비하여 측정될 수 있으며, 교육을 통해 학습자가 개선될 수 있는 지식, 기술, 태도의 집합체라고 역량을 정의하였다. Sparrow (1996)는 역량을 조직 (핵심)역량, 관리역량, 개인 (직무)역량 세 가지로 구분하였으며, 세 가지 역량은 서로 긴밀하게 연관되어 있다고 주장하였다.

Mirabile (1997)는 역량의 구성요소로 우수 성과자의 지식, 기술, 동기, 신념, 가치, 능력, 특성으로 구분하였으며, Lucia and Lepsinger (1999)는 효과적으로 업무를 수행할 수 있게 만들어주는 지식과 기술 특성의 조합으로 역량을 정의하였다. Kim (2001)는 조직의 전략 및 미션을 달성하기 위해 요구되는 개인의 지식, 기술, 태도의 총체라고 역량을 정의하였다. 앞선 선행연구를 바탕으로 역량을 정의한다면, 역량이란 "우수한 성과를 낼 수 있게 영향을 주는 지식, 기술, 특성 등을 포함한 개인의 특성"으로 정의될 수 있다.

\subsection{2. 역량모델의 정의}

McLagan (1989)은 역량모델이란 개인이 주어진 역할을 성공적으로 수행하고, 성과창출에 기여한 핵심적인 지식, 가치, 행동을 체계화시킨 것으로 정의하였다. Mansfield (1996)는 종업원들이 효율적으로 업무를 수행하기 위해 필요한 행동과 
능력을 세부적으로 기술한 것으로 역량모델을 설명하였으며, Lucia and Lepsinger (1999)는 역량모델을 활용하면 정확한 기술의 차이를 파악할 수 있고, 경쟁우위를 확보할 수 있는 필수 역량과 구체적 실천사항을 획득하여, 생산성을 극대화할 수 있는 도구라고 주장하였다.

Kwon (2003)은 역량모델은 뛰어난 성과를 내기 위해 필요한 행동 수준을 보여주는 지도로써, 조직이 기대하는 성과를 높이고, 핵심 전략의 하위조직과 개인의 방향을 일치시켜 구성원들이 어떤 방법으로 기대를 완수해야 하는지 이해를 돕는 것이라고 주장하였다. Le Deist and Winterton (2005)은 조직의 전략과 인적자원개발의 연계를 위한 메커니즘이며, 조직의 목표를 달성하기 위해 도움을 주는 지식, 기술, 행동을 설명하기 위한 도구라 정의하였다. Park (2002)은 조직과 개인의 성과달성을 위해 필요한 역량을 규명하고, 도출된 결과로 나타난 역량들과 인적자원시스템 전체에 활용할 수 있는 도구로 정의하였다.

앞선 선행연구를 바탕으로 역량모델을 정의하였을 때, 역량모델이란 "성과달성을 위해 필요한 역량을 규명하며, 규명된 역량을 체계화하여 우수한 성과를 도출하기 위한 행동에 대한 세부 내용을 기술한 것"으로 정의될 수 있다.

\subsection{3. 대학생 역량 관련 선행연구}

창직에 대한 선행연구를 살펴보았듯이, 창직에 대한 연구뿐만 아니라 창직역량에 대한 연구는 현재까지 매우 부족한 실정이다. 따라서 본 연구의 대상인 대학생 창직역량에 대한 선행연구 또한 미비하다. 이를 보완하기 위해, 본 연구의 대상인 대학생 역량에 대한 선행연구를 분석하였다.

Lee and Kim (2012)은 대학생의 핵심역량 수준의 변화와 학업성취도의 관계를 규명하기 위해 K-CESA (한국직업능력개발원 개발)에서 개발한 의사소통 역량, 글로벌 역량, 자원·정보·기술의 활용역량, 종합적 사고력, 대인관계 역량, 자기관리 역량 척도를 활용하였다. 그 결과 대학생의 핵심역량 지표는 학점 평균과 차별점이 있는 학업 성취도 지표로써 작용될 수 있으며, 이를 근거로 대학교육의 성과지표가 학점평균이 아닌 대학생 핵심역량이 대학교육의 성과지표로 활용될 수 있음이 확인되었다.

Noh and Lee (2013)는 대학생 역량진단 도구 개발 및 타당화를 검증하기 위한 연구를 수행하였다. 구체적으로는 역량 별 잠정적 구성요소를 도출, 예비문항 작성, 문항별 수준 부여, 예비조사, 본조사를 거쳐 대학생 역량진단을 위한 도구가 개발되었다. 역량진단도구 개발로, 대학이 추구하고자 하는 가치, 인재상 등을 보다 구체적으로 확인할 수 있었으며, 대학의 지향점과 목표, 차별성을 이해할 수 있었다. 또한, 개개인이 보유하고 있는
역량수준을 확인하여 자기개발 및 진로결정을 위한 정보로 제공될 수 있다는 점에서 의의가 있음을 시사하였다.

Jin (2013)은 수도권 및 지방 대학생 핵심역량 격차에 대한 연구를 실시하였으며, 그 결과 대학 소재지에 따른 핵심역량의 차이가 있으나, 상대적으로 낮은 수준의 핵심역량을 갖춘 지방 대학생이 학년이 높아질수록 수도권 대학생과의 격차가 줄어진다는 결론을 도출하였다.

Lee (2014)는 D 여대 신입생의 핵심역량 진단결과와 D 여대 단과대학별 핵심역량 비교분석을 연구하였으며, D 여대 신입생 역량군과 단과대별 D 여대 신입생의 역량 차이가 유의미함을 도출하였다. 이에 따라, Lee (2014)는 신입생 선발 시 D 여대의 역량모델과 진단도구를 활용한 선발 도구의 정교화를 통해 $\mathrm{D}$ 여대의 인재상에 부합하는 인재를 선발해야 한다고 주장하였다.

Lim, Park, and Kim (2015)는 대학생 역량모델 구축 연구를 위해 문헌분석, 타 대학 벤치마킹, 사례연구, 기업 인재상 분석, 보직교수 심층 인터뷰, 기업 인사 담당자 인터뷰를 실시하였다. 그 결과 대학생 역량모델을 잠정 도출하였으며, 잠정 도출된 역량모델의 행동지표 개발 및 타당화 검증, 역량모델 완성 후 파일럿 테스트를 통해 대학생 역량모델을 구축하였다. Lim et al. (2015)은 대학생 역량모델 개발을 통해 기업이나 기타 조직의 역량모델과 대학생 역량모델의 차이점이 있음을 시사하였으며, 대학의 역량모델은 모든 학생들이 갖춰야 할 공통역량에 초점을 두어야 한다고 주장하였다. 또한, 교육기관의 목표 및 비전이 역량모델에 영향을 준다는 것과 각 단과대학에 따른 역량의 중요도 차이가 있음을 결과로 도출하였다-

앞선 선행연구를 바탕으로 종합해 오면, 대학생 역량은 학업성취 정도에 대한 지표, 현재 대학생 역량수준의 기준제시, 교육기관의 지향성과 부합하는 인재를 육성하기 위한 도구로써 활용, 기업 및 기타기관과 교육기관의 역량모델에 차이가 있음을 알 수 있었다. 또한, 선행연구를 통해, 본 연구의 주제인 대학생 창직역량을 개발하기 위한 역량모델 절차에 대해서도 파악할 수 있었다.

\section{3. 프랜차이즈에 대한 연구}

\subsection{1. 프랜차이즈의 정의}

Kim and Lee (2019b)에 따르면 프랜차이즈 (Franchise)는 세 가지로 정의될 수 있다. 첫째, "가맹본부가 가맹점사업자에게 자신의 상품과 서비스를 더욱 효과적으로 판매하기 위해서 일정한 지원-교육을 수행하고 가맹비를 받는 관계", 둘째 "가맹본부가 가맹사업자에게 가맹본부의 상품과 서비스를 판매하며, 그 외에 기타 영업을 할 수 있는 권리를 부여하는 포괄적 거래 관계", 셋째, "가맹본부와 가맹점사업자 간의 일정한 계약관계이고 가맹본부는 
경영 노하우와 교육훈련 등의 업무에 관하여 지속적인 이익을 제공하고, 가맹점사업자는 가맹본부의 소유 또는 관리 하에서 영업을 하며, 프랜차이즈 사업에 대하여 자신의 자본을 직접 출자하는 것이라고 정의한다 (Kim \& Lee, 2019b; Beak, 2018; Kim, 2011)." 즉, 프랜차이즈의 다양한 정의를 통해 프랜차이즈란 "프랜차이즈 가맹본부와 가맹점 간의 거래관계"로 규정될 수 있다 (Kim \& Lee, 2019a).

\subsection{2. 국내 프랜차이즈 현황}

국내 프랜차이즈는 2012 년부터 가맹본부 수, 브랜드 수, 가맹점 수가 연 5 10\%씩 지속적으로 증가하고 있다. 업종별로는 가맹본부·가맹점에서 외식업, 서비스업, 도·소매업으로 구분된다 (Fair Trade Commission, n.d., 2019; Kim \& Lee, 2019b). 공정거래위원회 가맹사업거래의 가맹본부 정보공개에 따르면, 2019 년 기준으로 국내 프랜차이즈 가맹본부는 총 5,175 개이며, 그 중 외식업이 3,861 개로 $74.6 \%$ 를 차지하고 있다. 가맹점 수에서도 전체 254,040 개 중 외식업이 122,574 개로 가장 많은 비율을 차지하고 있다 (Fair Trade Commission, n.d., 2020). 프랜차이즈 업종별로 평균 존속 기간에 대한 조사에 따르면, 외식업의 브랜드 평균 존속 기간은 6 년 5 개월, 서비스 업종은 평균 8 년, 도·소매 업종은 평균 11 년 3 개월로 나타났다 (Fair Trade Commission, n.d., 2020). 즉, 가장 많은 비율을 차지하는 외식업의 존속기간이 가장 짧으며, 다른 업종 또한 약 10 년 정도 유지한다는 사실을 비추어 보았을 때, 가맹점 수를 유지하기 위해서는 가맹사업자와 가맹점주, 슈퍼바이저에 대한 지속적인 역량연구가 필요하다. 그러나, 현재 프랜차이즈 관련 연구를 살펴보면, 가맹사업자 및 가맹점주에 대한 역량 연구는 부족하며, 대부분 프랜차이즈 가맹본부의 슈퍼바이저의 역량에 대한 주제가 대다수를 차지한다 (Kim \& Lee, 2019a).

창직을 준비하는 대학생이 창직 후 가맹사업으로 창직영역을 확장하기 위해서는 가맹사업자의 역량에 대한 선행연구가 필요하나, 관련 연구가 미비한 관계로 프랜차이즈 관련 역량 연구로 선행연구의 범위를 넓혀 진행하였다.

\subsection{3. 프랜차이즈 역량 관련 선행연구}

창직 후 프랜차이즈 영역까지 범위를 넓히기 위해서는 창직자가 가맹사업자가 되어야 한다. 때문에, 창직 후 프랜차이즈 영역으로 사업을 확장을 희망하는 창직자는 가맹사업자가 갖춰야 할 역량에 대해 미리 인지를 하고 습득할 필요가 있다. 그러나, 앞서 언급하였듯 프랜차이즈 역량연구 중 가맹본부를 운영하는 가맹사업자의 역량연구나 가맹점을 운영하는 가맹점사업자에 대한 역량연구는 부족한 실정이며, 가맹본부에서 직무를 수행하는
슈퍼바이저 역량에 대한 연구가 가장 활발히 진행되고 있다. 따라서, 본 연구에서는 프랜차이즈 관련 연구를 슈퍼바이저 영역까지 넓혀 탐구하였다.

Lee (2012)는 외식 프랜차이즈 슈퍼바이저의 핵심역량에 대한 상대적 중요도와 우선순위에 관한 연구에서 슈퍼바이저를 "여러 개의 가맹점에 가맹본부가 제공하는 정보를 전달해 주고 가맹점 영업활동이 원활하게 운영될 수 있도록 관리하거나 지도해 주는 사람"이라 정의하였으며, AHP 기법을 활용하여 '매장운영관리요인', '재무관리요인', '인적자원관리요인', 마케팅관리요인'을 슈퍼바이저의 핵심역량으로 도출하였다. Seo (2012)는 프랜차이즈 기업의 핵심역량과 시장지향성 연구에서 프랜차이즈 기업의 내부역량에 대한 중요성을 주장하며, 프랜차이즈 기업의 대표이사, 임원, 본부장, 경영지원담당 대상으로 설문조사를 실시하였다. 이를 바탕으로 환경 불확실성에 프랜차이즈 기업이 대응하기 위해서는 핵심 역량을 활용하여 환경 불확실성과 관련된 기업의 경영상 이슈를 극복하는 힘을 배양함을 주장하였다. 또한, 가맹점주 경영에 필요한 역량을 지속적으로 실행할 수 있도록 핵심역량 매뉴얼이 필요함을 주장하였으며, 핵심역량의 지속적인 배양과 더불어 조직 내 시장지향성을 강조해야 함을 연구의 결과로 도출하였다.

Lee (2015)는 슈퍼바이저의 역량이 신뢰기반구축을 통한 관계성과에 미치는 영향에 관한 연구를 실시하였으며, 슈퍼바이저의 역량이 우수할수록 고객과 컨설턴트 사이의 신뢰관계가 유의미한 영향을 미치며, 가맹본부의 경영성과와 기업가치를 높이기 위해서는 슈퍼바이저의 역량 향상과 슈퍼바이저와 가맹점주 간의 신뢰관계 구축이 필요함을 주장하였다. Kim (2016)은 슈퍼바이저 핵심역량이 가맹본부의 관계의 질, 재무적 성과, 재계약의도에 미치는 영향 연구를 통해, 슈퍼바이저의 핵심역량 중 매장운영관리능력의 하위요소인 가맹점 문제해결능력이 가맹본부와 가맹점주간의 관계의 질에 중요한 영향을 미친다는 연구결과를 도출하였다. 또한, 슈퍼바이저의 핵심역량인 재무적 성과도 가맹본부와 가맹점주 간의 관계의 질에 중요한 변수로 작용한다는 점도 연구결과로 제시하였다.

Choi (2017) 또한, 외식 프랜차이즈 가맹본부의 슈퍼바이저 핵심역량이 가맹점의 신뢰와 경영성과에 미치는 영향이라는 연구를 통해 슈퍼바이저의 역량이 우수할수록 가맹점과 인지적인 신뢰, 감정적 신뢰에 긍정적인 영향을 미침을 결과로 도출하며, 슈퍼바이저의 역량을 지속적으로 강화할 방안을 고려해야 함을 주장하였다.

Kim and Lee (2019a)는 외식 프랜차이즈 가맹점주의 역량개발에 관한 기초 연구를 통해 가맹점주의 역량을 총 3 개의 역량군, 13 개의 세부 역량을 도출하였으며, 슈퍼바이저의 필요역량과 가맹점주의 역량이 상이함을 주장하였다. 또한, 각 역량에 대한 
세부지표를 개발하여 프랜차이즈 사업 분야를 확장시키기 위한 세부 행동을 제시하였다. 후속연구로, Kim and Lee (2019c)는 외식 프랜차이즈 가맹점주의 필요 역량을 The Locus for Focus 모형으로 분류하여 가맹점주들이 우선적으로 개발해야 할 필요역량을 도출하였다.

앞서 언급하였듯, 프랜차이즈 역량 연구는 대부분 프랜차이즈의 슈퍼바이저의 역량을 중심으로 연구가 진행되었으며, 일부 연구에서 가맹점주의 역량에 대한 연구가 진행되었음을 알 수 있었다. 하지만 프랜차이즈를 희망하는 창직자와 창업자에 대한 역량연구는 미비함을 발견할 수 있었다. 따라서, 본 연구는 프랜차이즈를 희망하는 창직자의 필요역량을 1 차적으로 도출하고 나아가 창직자가 프랜차이즈 사업으로 확장시키기 위한 방향성을 제언하고자 한다.

\section{3. 연구설계}

\section{1. 연구절차}

\subsubsection{Spencer and Spencer 의 역량사전}

1981 년 Boyatzis 는 어느 조직에서나 우수 성과자들의 역량이 일관성 있게 발견된다는 사실을 발견했다. 1989 년 Spencer and Spencer 는 Boyatzis 가 발견한 내용을 바탕으로 200 여 가지의 업무와 관련된 역량을 수집 및 분석하였고, 그 결과 일반 역량모델 (Generic Competency Models)을 개발하였다 (Spencer \& Spencer, 1993). 일반 역량모델은 기술직·전문직, 판매·마케팅·무역업, 대인 서비스업, 기업가, 기업체의 관리직, 정부, 구 기관, 교육기관, 종교 단체 및 의료기관 업종을 포함하고 있으며, 286 개의 역량모델을 기초로 6 개의 역량군과 21 개의 세부 역량으로 구성 (Kim \& Lee., 2019a)하였다. Spencer and Spencer (1993)의 역량사전은 내적인 의도 수준에서 역량들을 범주화 하였으며, 역량수준을 척도화 하였다.

그러나 Spencer and Spencer (1993)가 개발한 역량사전은 다양한 직무를 포괄하고 있지만, 일반적인 형태로 제시되었기 때문에 몇 가지 한계점이 존재한다. 첫째, 정확성 부분이다. Spencer and Spencer (1993)의 역량사전이 200 여 가지의 역량모델을 검토하여 역량사전을 개발하였기 때문에 모든 업무에 적용시킬 수 있지만, 일반화되어 있기 때문에 연구하려는 분야에서 정확한 역량을 측정하기엔 한계점이 존재한다. 둘째, 일반 역량 척도는 21 개의 공통역량만을 대표한다. 따라서 각 직무 별 특정 역량에 대해서는 포괄하지 못한다는 한계점을 가지고 있다.
하지만 이러한 한계점에도 불구하고, 본 연구에서 Spencer and Spencer (1993)의 역량사전을 활용한 이유는, 창직교육 및 창직활동이 진행되고 있으나 '창직역량'에 대한 기존 연구가 소수인 관계로, 일반적으로 널리 범용 되고 있는 '일반 역량모델'을 활용하여 기준점으로 제시하고 창직 특성에 맞춘 추가 역량을 제시하는 것이 합리적이라고 판단하였다.

따라서, 본 연구에서는 Spencer and Spencer (1993)의 역량사전을 바탕으로 창직역량을 도출한 후, 추가적인 역량은 새롭게 추가 및 정의하여 창직역량을 도출하였다.

\subsubsection{Spencer and Spencer 의 역량모델 개발 절차}

Spencer and Spencer (1993)는 역량모델 개발 방법으로 세 가지 방법을 제시하였다. 첫 번째 준거 집단을 이용한 고전적 연구, 두 번째 전문가 패널을 이용한 단축형 연구, 마지막으로 미래형 직무 혹은 1 인 직무에 대한 연구이다. 그 중, 미래형 직무 혹은 1 인 직무에 대한 역량개발은 현재 존재하지 않는 직무 혹은 해당 직무에 종사하는 사람이 단 한 명에 불과할 때 사용하는 방법이므로 특수한 상황에서만 사용된다. 고전적 연구는 우수 기준 척도 규명, 준거 집단, 자료 수집의 단계가 명확히 구분되어 있으나 단축형 연구는 해당 단계를 전문가 패널을 통해 의견을 수집 및 취합함으로써 연구 단계를 단축한다는 차이점을 가지고 있다. 또한, 고전적 연구가 자료수집 (인터뷰, 설문지 배포, 문헌고찰 등)의 다양한 방법으로 자료를 취합하는 것에 비해, 단축형 연구는 행동사건면접을 통하여 구체적 사건에서 공통적으로 대처하는 태도 및 방법을 분석하여 목록화 한다는 차이점이 있다.

본 연구의 핵심 주제인 창직역량은 선행연구가 부족하고 준거 집단 지정을 할 수 있는 기준이 한정되어 있어, 고전적 연구를 통해 역량을 도출하기에는 한계가 존재하였다. 따라서, 창직역량을 도출하기 위해 고전적 방법과 전문가 패널의 의견을 취합하는 단축형 연구를 혼합하여 대학생 창직역량을 도출하기 위한 연구를 진행하였다.

\subsection{3. 연구의 절차}

본 연구의 절차는 Figure 1 과 같다. 먼저, 창직에 대한 선행연구와 관련 논문이 부족한 관계로 탐색적 연구를 통해 창직역량을 파악하였다. 우수 선별된 우수 사례자의 경우 D 여대의 창직 팀 중 창직어워드에 진출한 학생들을 대상으로 BE (Behavioral Event Interview)와 FGI (Focus Group Interview)가 실시되었다. BE 와 FGI 를 통해 공통된 역량을 도출한 뒤, 창직과정 담당자를 통해 도출된 역량에 대한 검증과 추가 요소를 점검 받았다. 또한, $\mathrm{HRD}$ 
전문가 인터뷰를 실시하여 도출된 역량에 대한 안면 타당도 검증을 거쳐 타당성을 얻고자 하였다.

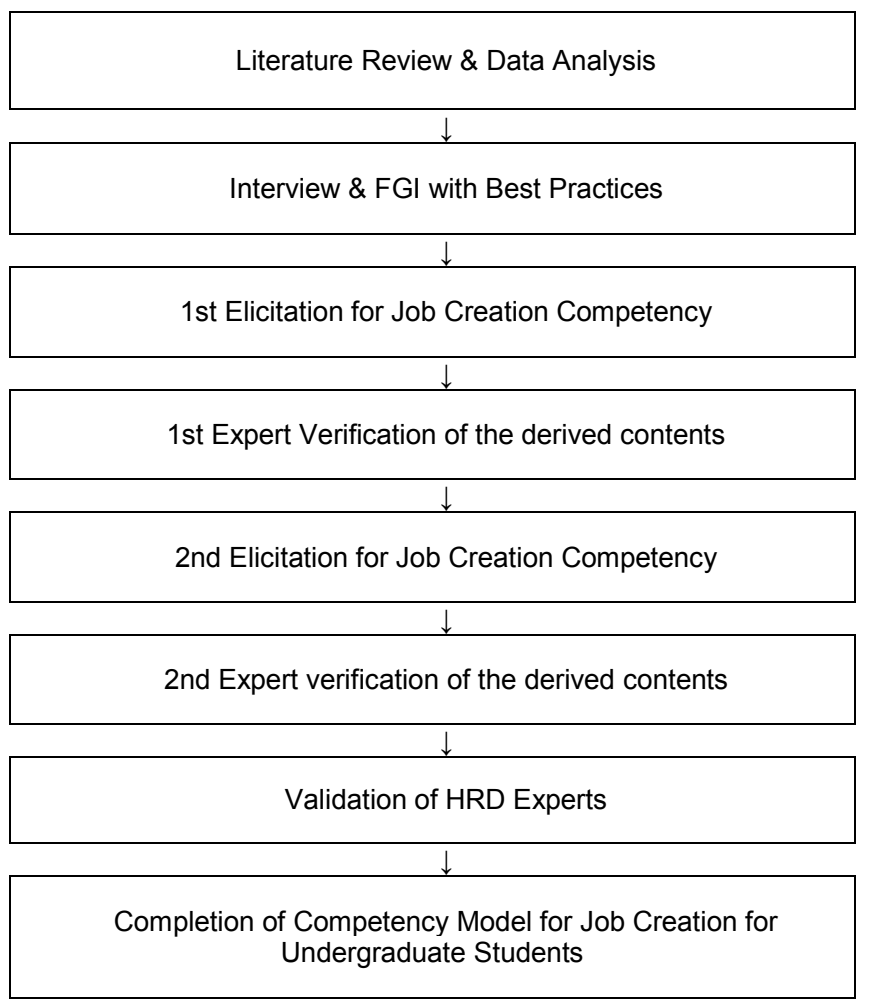

Figure 1: Research Process

\subsection{4. 인터뷰를 위한 행동사건면접 (BEI) 구성}

Spencer and Spencer (1993)는 역량 연구는 인터뷰 대상자의 동기나 스킬에 대해 응답하는 것은 신빙성이 낮으며, 실제로 직면한 중대 상황에서 나타낸 행동만이 믿을 수 있다고 주장하였다. Spencer and Spencer (1993)의 주장과 더불어 선행연구가 부족한 본 연구에서 창직역량을 도출하기 위해서는 우수 사례자들의 인터뷰를 활용하여 최대한 많은 역량을 도출하는 것이 적합하다고 판단되었다. 따라서, 창직역량을 도출하기 위한 방법으로 행동사건면접 (Behavioral Event Interview)이 활용되었다.

행동사건면접을 진행하기 위해 문항 구성은 STAR (Situation, Task, Action Plan or Attitude, Result)기법에 기반한 질문이 구성되었다. 질문의 상세내용은 창직과정 활동 시 성공 혹은 실패 상황이나, 팀원에 대한 내용, 성공 및 실패 사례에서 대처했던 방법, 결과 및 성과 등을 중심으로 구성되었다.

또한, 상세한 내용을 파악하기 위하여 사전에 인터뷰 문항 일부분이 제공되었으며, 우수 사례자는 해당 질문에 대한 답변을 미리 구성해 옴으로써 한정된 인터뷰 시간을 효과적으로
사용하였다. 실제 인터뷰 수행 시 답변에 따른 추가 질문을 사용했으며 상황에 따라 문항이 변형되거나 축소되었다.

\section{2. 연구대상}

\subsection{1. 창직과정 우수 사례 대학생 인터뷰 대상자}

본 연구 인터뷰 대상자는 2019 년 청년취업아카데미 창직과정을 수료한 학생 중, 창직어워드에 진출하여 수상한 $\mathrm{D}$ 여대 학생을 대상으로 실시하였다. $\mathrm{D}$ 여대 학생들이 참가한 창직어워드는 1$)$ 창직 수행기관에 협업하고 있는 대학의 대표 선출, 2) 창직 수행기관 대표 선출, 3) 창직어워드 진출의 순서로 되어 있으며, 창직 수행기관이 관리하는 약 80 의 팀 중 수행기관 별 각각 약 10 개 15 개 대표를 선출하여 총 30 45 개의 팀이 창직어워드에서 창직아이디어에 대한 최종평가를 심사받으며, 최종 대상은 '고용노동부 장관상'을 금-은-동상은 '한국산업인력공단 이사장'명의의 상을, 장려상은 각 창직운영기관 회장상을 수상하게 되어있다. 인터뷰에 참가한 학생들은 스스로 창직을 희망하여 해당 프로그램에 참여한 학생이며, 인터뷰 대상은 총 10 명이다. 상세 내용은 Table 3 와 같다.

Table 3: Best Practices Profile

\begin{tabular}{|c|c|c|c|c|}
\hline & Name of Job & grade & Awards & $\begin{array}{c}\text { Research } \\
\text { Method }\end{array}$ \\
\hline A & \multirow{3}{*}{$\begin{array}{l}\text { Improvement of } \\
\text { eating habits for } \\
\text { children }\end{array}$} & 2nd & \multirow{3}{*}{$\begin{array}{l}\text { Awarded for } \\
\text { Chairman of the } \\
\text { HRD Service of } \\
\text { Korea }\end{array}$} & \multirow{6}{*}{$\mathrm{BEI}$} \\
\hline$B$ & & 2nd & & \\
\hline C & & $3 r d$ & & \\
\hline$D$ & \multirow{3}{*}{ Vegetarian Planner } & 4th & \multirow{7}{*}{$\begin{array}{c}\text { Awarded for } \\
\text { Chairman of the } \\
\text { Korea Productivity } \\
\text { Center }\end{array}$} & \\
\hline$E$ & & $3 r d$ & & \\
\hline $\mathrm{F}$ & & 2nd & & \\
\hline$G$ & \multirow{4}{*}{ Shared Designer } & 4th & & \multirow{4}{*}{$\mathrm{FGI}$} \\
\hline $\mathrm{H}$ & & 4th & & \\
\hline 1 & & 4th & & \\
\hline $\mathrm{J}$ & & 4th & & \\
\hline
\end{tabular}

\subsection{2. 창직 전문가 및 HRD 전문가 심층 인터뷰 대상}

창직 전문가는 Table 4 와 같이, 청년취업아카데미 창직과정을 고용노동부와 한국산업인력공단에서 위탁받아 운영중인 기관의 종사자로 선정되었으며, 특히 대학생 창직과정이 시행된 2013 년부터 현재까지 수행하고 있는 전문가에게 창직역량에 대한 인터뷰 및 검토가 요청되었다. HRD 전문가는 창직에 대한 이해와 
$\mathrm{HRD}$ 경력을 모두 갖춘 대학교 교수와 창업관련 업무를 수행하면서 HRD 박사과정 중인 전문가를 대상으로 선정하였으며, 창직역량에 대한 역량의 정의, 역량군, 역량에 대한 세부행동에 대해 검토를 요청하였다.

Table 4: Expert Profile

\begin{tabular}{|c|c|c|c|c|}
\hline \multicolumn{2}{|c|}{ Classification } & Affiliation & Position & $\begin{array}{r}\text { Career } \\
\text { Period }\end{array}$ \\
\hline $\begin{array}{c}\text { Expert of } \\
\text { Job } \\
\text { Creation }\end{array}$ & 1 & $\begin{array}{c}\text { Operation institution } \\
\text { of Job Creation }\end{array}$ & Team leader & 20years \\
\cline { 2 - 5 } & 2 & $\begin{array}{c}\text { Operation institution } \\
\text { of Job Creation }\end{array}$ & Researcher & $\begin{array}{c}5 y e a r s \\
6 \text { months }\end{array}$ \\
\hline $\begin{array}{c}\text { Expert of } \\
\text { HRD }\end{array}$ & 1 & $\begin{array}{c}\text { Professor in Dept. } \\
\text { HRD in University }\end{array}$ & Professor & 21years \\
\cline { 2 - 5 } & 2 & $\begin{array}{c}\text { Start-up Center in } \\
\text { University }\end{array}$ & Team leader & 16years \\
\hline
\end{tabular}

\section{3. 연구방법}

\subsection{1. 문헌연구}

문헌연구를 통해 역량모델의 개념 및 역량모델의 절차에 대하여 고찰하였다. 이를 바탕으로 본 연구의 주제인 '대학생 창직역량 개발을 위한 탐색적 연구'에 대한 방법론을 결정하였다. 방법론을 결정한 후, 창직역량 개발과 관련된 연구를 고찰하여 현재까지 관련 선행연구가 많이 축적되지 않았음을 확인하였다. 따라서 본 연구의 대상인 대학생의 역량에 대한 연구를 통하여 연구방법 및 절차 등 주제의 범위를 넓혀 문헌연구를 수행하였으며, 문헌연구 중 창직역량 도출 시 유의미한 관계가 있다고 판단되는 대학생 역량은 인터뷰 질을 향상시키기 위해 인터뷰 문항으로 추가되었다.

\subsection{2. 창직과정 우수 사례 대학생 인터뷰}

청년취업아카데미 창직과정 수료생 중, 창직어워드에 진출한 학생을 대상으로 BE 또는 FGI 기법으로 인터뷰를 실시하였다. 인터뷰 형태를 BEI 또는 FGI 두 가지 형태로 실시한 이유는, 각 팀이 창직과정 전에 일면식 없이 대상자가 모여 팀을 구성한 팀과 학부 1 학년 때부터 현재까지 함께 학과 생활을 하며 서로 익숙한 학생들이 구성한 팀의 특성이 다를 것이라 판단되었기 때문이다. 따라서, 창직명 '아동식습관 ***'과 '베지 ***'는 BEI 를, 창직명 '공유가치 ${ }^{* \star \star \prime}$ '는 FGI 기법이 사용되었다. 인터뷰와 FGI 는 회차 당 약 2 시간 정도 소요되었으며, 인터뷰에 대한 기록은 사전 동의를 구하고 녹음이 진행되었다. 인터뷰와 FGI 는 모든 내용을
전사하였으며, 인터뷰에 대한 추가적인 문의 사항은 전화 혹은 메신저를 통해 보충 질의응답이 진행되었다.

\subsection{3. 창직 전문가 및 HRD 전문가 $1: 1$ 인터뷰}

창직 전문가 인터뷰는 우수 사례 대학생 인터뷰로 도출된 결과를 바탕으로 진행하였다. 우수 사례 대학생들이 응답한 내용을 정리하여 구성한 역량에 대한 의견과 추가 및 삭제되어야 할 역량을 검토하였으며, 인터뷰 시간은 1 인당 약 2 시간 정도 소요되었다. 인터뷰는 연구자가 직접 찾아가 실시하였으며, 동의를 구하고 녹음과 축어록 작성을 하였다. 또한, 인터뷰 후 추가적인 내용은 전화, 메신저, e-mail 을 활용하여 보충되었다.

문헌연구와 우수 사례 대학생 인터뷰를 통해 역량요소를 도출한 후, 전문가 인터뷰로 수정 보완된 대학생 창직역량 모델이 잠정적으로 도출되었다. 잠정 도출된 대학생 창직역량 모델의 타당성을 검토하기 위해 창직 전문가에게 2 차 검토 및 보완 과정을 거쳐, $\mathrm{HRD}$ 전문가 2 인에게 추가로 내용을 확인하여 타당성이 확보되었다. 그리고 공식 인터뷰 후, 필요에 따라 전화 및 메일로 인터뷰를 진행하였으며 이를 바탕으로 대학생 창직역량에 대한 정의와 세부 내용이 보완되었다.

\section{4. 연구결과}

\section{1. 대학생 창직역량 1 차 도출 결과}

창직역량 1 차 도출 내용은 창직과정 우수 사례 대학생 인터뷰 후, 내용 분석을 통해 도출하였다. 인터뷰 시 질문은 행동사건면접 (BEI)을 활용하여 우수 사례 대학생들이 창직과정을 경험하면서 실제로 직면 했었던 중대 상황을 중심으로 질의되었다. 질의 내용은 당시 상황, 관련 과업, 관련된 인물, 해결방안 그리고 그에 따른 결과를 주요 내용으로 하였다.

인터뷰 후, 녹취록을 작성하여 확보한 자료는 주요 사건 중심으로 인터뷰 대상자가 취했던 공통된 행동 또는 인터뷰 대상자가 발언한 주요 키워드를 중심으로 선별되었다. 선별된 행동과 키워드는 다시 공통점을 찾아 하나의 묶음으로 구성되었다. 그 후 Spencer and Spencer (1993)의 역량사전의 내용과 일치시키는 작업을 거쳤으며, 역량사전의 21 개 역량 중 10 개의 역량과 매칭하였고 시장감지역량을 추가하여 총 11 개의 역량 (성취 지향적 역량, 주도성 역량, 대인이해역량, 팀워크와 협력 역량, 팀 리더십 역량, 분석적 사고 역량, 개념적 사고 역량, 자기확신 역량, 
유연성 역량, 조직 헌신 역량, 시장 감지 역량)을 도출하였다. 역량의 정의와 구체적 내용은 Spencer and Spencer (1993)의 역량사전의 정의를 기본으로 하여 창직에 맞게 변형되었다.

\section{2. 대학생 창직역량 2차 도출 결과}

1 차 도출된 창직역량을 바탕으로 두 명의 창직 전문가에게 역량 검토 및 추가의 과정을 거쳤다. 인터뷰에서 창직 전문가는 1 차로 도출된 시장감지역량과 분석적 사고 역량을 세분화하길 요구하였다. 이에 따라, 시장감지역량과 구분되는 정보탐색역량을, 분석적 사고 역량과 구분되는 문제해결역량을 추가하였다. 연구자는 정보탐색역량과 문제해결역량에 대한 정의와 구체적 행동을 구성한 후, 창직 전문가에게 서면으로 2 차 검토를 받았다.

"시장감지 역량은 창직을 희망하는 학생이 감각적으로 체감하고 기회를 포착하는 능력이라면, 정보탐색역량은 신빙성 있는 데이터를 수집하고 유관 현상과 연계하여 분석하는 능력이라 차이가 있다. 따라서, 해당 역량은 다른 역량으로 분리하는 것이 맞다고 생각된다."

- 전문가 인터뷰 중 일부 내용 발췌 -

위와 같은 창직 전문가의 의견 등을 따라 1 차 도출된 11 개의 역량과 통합하여 총 13 개의 역량으로 완성하였다. 추가된 역량은 다음과 같은 특징을 지닌다. 첫째, 시장감지역량이 창직준비자의 개별 경험과 환경에 의지한 역량이라면, 정보탐색역량은 실제 수치화 된 정량적 정보를 찾을 수 있는 능력이라는 점에서 구분된다. 둘째, 문제해결역량은 분석적 사고 역량을 수행하기 위한 선행행동으로 판단되었고, 해당 역량을 추가하여 창직 대상자의 역량이 세분화되었다.

\section{3. 대학생 창직역량 최종 도출 결과}

창직역량은 1 차 도출된 11 개의 역량과 창직 전문가 2 인의 검토를 받아 추가된 2 개의 창직역량으로 총 13 개의 창직역량을 도출하였다. 이를 토대로 창직역량에 대한 최종 검토를 창직교육 및 창업관련 업무에 종사하고 있는 HRD 전문가에게 도출된 역량명과 정의, 그리고 역량의 행동지표가 알맞게 기술되었는지에 대해 인터뷰 및 서면 검토를 요청하였으며, $\mathrm{HRD}$ 전문가의 피드백에 따라, 역량군, 역량명, 정의, 구체적 행동으로 나누어 창직역량을 정리하였다. Table 5 은 최종 검토로 도출된 창직역량이다.
최종 도출된 창직역량은 성격에 따라, 개인 가치 역량군, 직무 역량군, 리더십 역량군으로 구분하였으며, 각 역량의 정의는 지식 (Knowledge), 기술 (Skill), 태도 (Attitude)의 기준에 맞춰 정의하였다. 또한, 각 역량에 대한 구체적 행동도 지식, 기술, 태도에 맞춰 수정하였으며, 각 구체적 행동에는 $\mathrm{K}, \mathrm{S}, \mathrm{A}$ 를 삽입함으로써 내용의 구체성이 보완되었다 (See Appendix 1)..

\section{5. 결론 및 제언}

\section{1. 결론}

본 연구의 목적은 창직을 준비하는 대학생들을 위한 창직역량 모델 개발을 위한 연구로, 창직을 준비하는 대학생들에게 필요한 역량을 도출하여 성공적으로 창직을 수행하고 나아가 창업과 프랜차이즈를 할 수 있는 기준을 제시하는 것에 목적이 있다.

이에, 창직과정 우수 사례자 인터뷰를 실시하여 우수 사례자의 공통역량을 도출한 후, Spencer and Spencer (1993)의 역량사전과 매칭하여 10 개의 역량을 도출하였으며, 역량사전에 게재되어 있지 않은 시장감지역량을 추가하여 11 개의 역량이 도출되었다. 도출된 11 개의 역량은 창직 전문가의 검토 및 의견을 반영하여 정보탐색역량, 문제해결역량 2 가지 역량이 추가되어, 총 13 개의 대학생 창직역량이 도출되었다.

도출된 대학생 창직역량은 $\mathrm{HRD}$ 전문가 의견을 반영하여 개인가치역량군, 직무역량군, 리더십 역량군으로 구분였다. 또한, 역량의 정의와 구체적 행동은 지식 (Knowledge), 기술 (Skill), 태도 (Attitude)의 기준에 맞게 수정되었다 (See Figure 2).

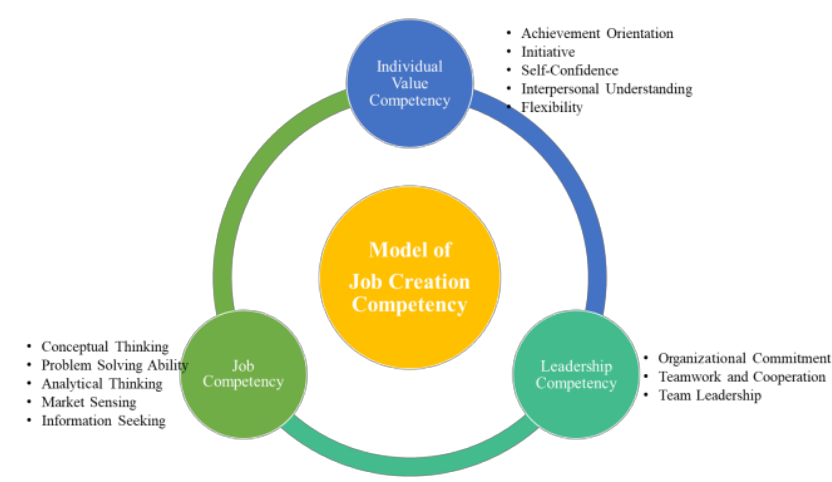

Figure 2: Model of Job Creation Competency

대학생 창직역량 역량모델은 Figure 2 와 같이 총 3 개의 역량군, 13 개 역량, 44 개의 구체적 행동으로 구성되었다. 대학생 창직역량 
중 개인 가치 역량군은 5 개, 직무 역량군은 5 개 리더십 역량군은 3 개의 역량으로 구성되었다. 또한, K, S, A 로 각 역량의 구체적 행동을 정의하였을 때, $\mathrm{S}$ 와 관련된 구체적 행동 15 개, $\mathrm{A}$ 와 관련된 구체적 행동 16 개, $\mathrm{K}$ 와 $\mathrm{S}$ 가 연계된 구체적 행동 8 개, $\mathrm{S}$ 와 $\mathrm{A}$ 과 연계된 구체적 행동 5 개로 구분되었다.

$\mathrm{K}$ 의 경우 단독 내용보다 $\mathrm{S}$ 와 연계된 구체적 행동이 많았는데, 그 이유는 창직활동이 단순 지식 습득이 아닌 이미 알고 있는 지식이거나 새로운 활동을 통해 습득한 지식을 활용하는 활동이기 때문에 구체적 행동 또한 $\mathrm{K}$ 와 $\mathrm{S}$ 가 연계된 내용으로 도출되었다고 판단된다.

\section{2. 연구의 시사점 및 제한점}

본 연구에서는 대학생 창직역량을 도출하여 역량모델로 제시하였다. 대학생 우수 사례분석과 전문가 (창직 전문가, HRD 전문가)의 검토로 총 3 가지 역량군, 13 개의 역량과 43 개의 구체적 행동을 도출하였다. 이에 따라 본 연구는 다음과 같은 시사점을 제공한다.

첫째, 대학생 창직역량 도출 및 역량모델 개발을 시도한 초기 연구라는 것이다. 국내 연구가 창직활동의 결과물인 창업과 관련된 연구는 활발하게 진행되어왔지만, 창직에 대한 연구는 미비하였다. 따라서, 창직을 준비하는 대상자에게 필요한 역량이 무엇인지 제시할 수 있는 실증적인 연구라는 점에서 의의가 있다. 또한, 나아가 프랜차이즈 창직 희망자를 위한 기초 연구가 될 수 있다는 점에서도 의의가 있다. 둘째, 본 연구에서 도출한 창직역량은 일회성으로 제시된 역량모델이 아닌, 향후 창직과 창업, 프랜차이즈를 준비하는 대학생들의 교육과정 개발의 기준점이 될 수 있다는 점에서 의의가 있다. 셋째, Spencer and Spencer (1993)가 제시한 일반역량모델을 근간으로 신규 분야의 역량모델을 개발하였다는 점이다. 이에 따라, 추후 창직과 관련된 다양한 연구를 할 수 있는 근간이 되었다는 점에서 의의가 있다.

그러나 이러한 시사점에서 불구하고 몇 가지 제한점을 지니고 있다. 첫째, 도출한 역량의 타당도 검증은 안면 타당도 (face validity)만을 이용하여 실시되어 양적 연구를 활용한 타당도 검증을 수행하지 못했다는 점에서 한계가 있다. 둘째, 본 연구에서는 우수 사례자의 사례분석을 기반으로 한 역량 도출로만 진행되었기 때문에 평균자 집단과의 차이점을 분석하는 과정을 진행하지 못하였다는 점이다. 셋째, 도출된 역량에 대한 구체적 행동을 제시하였으나, 행동의 수준을 단계화시키지 못했다는 점에서 한계가 있다. 마지막으로 대학생 창직역량 도출 후 프랜차이즈 가맹사업자 역량과 비교하지 못했다는 점이다. 창직역량과
가맹사업자의 역량에 대한 비교를 통해 공통 역량을 도출하고자 하였으나, 선행된 프랜차이즈 역량 연구에서는 가맹사업자가 갖춰야 할 역량보다는 프랜차이즈 직무 중 하나인 슈퍼바이저의 역량에 대한 연구가 대다수였으며, 연구된 슈퍼바이저의 역량 또한 직무 중심의 역량으로 대다수가 한정되어 있어 창직역량과 비교하기에는 한계가 존재하였다.

본 연구의 시사점과 제한점을 반영하여 다음과 같은 내용의 후속 연구를 제안한다. 첫째, 본 연구에서 도출한 창직역량에 대해 일반화 검증을 실시하여 창직역량의 타당도를 재검증할 필요가 있다. 둘째, 도출된 창직역량에 대해 우수 사례자 뿐만 아니라 평균자 집단 연구를 실시하여 창직역량에 대한 당위성을 확보하는 연구가 필요하다. 셋째, 창직역량의 행동 수준 단계화 연구를 실시하여 창직을 준비하는 대상자들의 현재 수준을 진단하고 필요 역량을 보완할 수 있게 해야 한다. 마지막으로 프랜차이즈 가맹사업자의 역량에 대한 연구진행과 이를 통해 도출된 역량을 창직역량과 비교함으로써 공통역량을 도출하고, 창직자가 프랜차이즈 사업으로 확장시킬 수 있는 역량을 미리 갖출 수 있도록 가이드를 제공해야 할 것이다.

\section{References}

Ahn, T. U. (2017). The influence of university entrepreneurship education's creativity capacity to the career preparation behavior - The mediation effect of entrepreneurship and selfefficacy. Doctoral dissertation, Chung-Ang University, Seoul, Korea.

Baek, J. S. (2018). A study on the influence of competence of franchise supervisor on sustainable business management of affiliates. Seoul, Korea: Master's Thesis in Chung-Ang University.

Choi, J. Y., Kim, H. N., \& Kim, D. K. (2017). The impact of university students' out-of-class experiences on students' core competency. Journal of Korean HRD Research, 12(2), 63-84.

Choi, T. S. (2017). The effects of core competencies of supervisors in food service franchise on franchisees' trust, and business performance. Journal of Foodservice Management Society of Korea, 20(5), 73-95.

Fair Trade Commission. (n.d). Statistical information of the franchise. Retrieved August, 1, 2020, from $\mathrm{http}: / /$ franchise.ftc.go.kr/main/subIndex/22.do

Fair Trade Commission. (n.d). Statistical information of the franchise. Retrieved August, 1, 2020, from https://franchise.ftc.go.kr/user/bbs/main/62/74/bbsDataList.do

Goo, B. M., Kim, K. H., \& Kim, J. K. (2010). Study on competency and competency model: Current state of competency model. Korean Association of Human Resource Development, 13(1), 131-154.

Han, C. Y. (2017). The effect of a restaurant franchise system on franchisee loyalty: Moderating role of supervisor competency. Doctorial dissertation, Sang-ji University, Wonju, Korea. 
Hwang, K. J. \& Lee, W. J. (2019). A study on the change of willingness to start up through youth employment education: Confirm the mediating effect of self-directed learning ability and creativity ability. Proceedings of Conference on Business Venturing, (pp.161-165). Seoul, Korea: Proceedings of Conference on Business Venturing Publishing.

Jin, M. S. (2013). An exploratory study on inequality of core competence of college students in Korea. Korean Journal of Sociology of Education, 23(1), 105-127.

Joo, C. A., Seo, Y. H., Lee, Y. N., Xie, L. L., \& Oh, S. G. (2015). The level of core competencies and importance of futureoriented core competencies between Korean and Chinese college students. Korean Journal of Comparative Education, 25(4), 203-233.

Kang, H. H., Park, W. J., \& Yun, B. B (2019). Impact of entrepreneurial business start-up motivation, entrepreneurial spirit, and entrepreneurial competence characteristics on startup companies' sustainability: Focusing on the mediating effect of the start-up companies' business performance. Asia-Pacific Journal of Business Venturing and Entrepreneurship, 14(3), 59-71.

Kim, B. Y. (2011). A study on the present condition of employees' service training in franchise beauty salons. Seoul, Korea: Master's Thesis in Sookmyung University.

Kim, D. Y. (2011). Study on entrepreneurship orientation in franchiser competency and franchiser organization upon franchise performance. Seoul, Korea: Master's Thesis in Chung-Ang University.

Kim, E. J. (2016). The effects of core competencies of supervisors on quality of relationship with the franchisor, financial performance, and agreement renewal intention: Focused on restaurant franchisees. Doctoral dissertation, Kyung Hee University, Seoul, Korea.

Kim, E. S. \& Lee, S. S. (2019a). A study on the development of competency model for restaurant franchise owners. The Korean Journal of Human Resource Development, 21(4), 2958.

Kim, E. S. \& Lee, S. S. (2019b). Systematic literature review for HRD in Korea franchise business. The Korean Journal of Franchise Management, 10(2), 33-47.

Kim, E. S. \& Lee, S. S. (2019c). Analysis of required competency for foodservice franchise Owner: The locus for focus model. The Korean Journal of Franchise Management, 10(4), 31-42.

Kim, H. J. (2019). The effect of value cognition on start-up competence and performance: Focusing on the moderating effects of business dependence. Doctoral dissertation, Jeon-ju University, Jeon-ju, Korea.

Kim, C. Y. (2017). Development and validation of creativity confluence competency test for university students. Doctoral dissertation, Soong-sil University, Seoul, Korea.

Kim, J. H. (2017). The effect of youth entrepreneur's Competence on entrepreneurial performance: Focusing on Moderating Effect of Government Support. Master's Thesis in Kwangwoon University, Seoul, Korea.

Kim, J. J., Choi, Y. S., Choi, H. Y., \& Huh, Y. S. (2016). Fundamental study on The Development of a Job Creation Program (1st year). Seoul, Korea: Korea Employment Information Service Publishing.

Kim, J. J., Choi, Y. S. \& Choi, H. Y. (2017). Fundamental study on
The development of a job creation program (2nd year). Seoul, Korea: Korea Employment Information Service Publishing.

Kim, J. J., Kim, H. J., \& Choi, Y. S. (2015). 2016 making our job: Middle age job creation guide. Seoul, Korea: Korea Employment Information Service Publishing.

Kim, J. J., Lee, Y. S., \& Kwon, S. B. (2014). 2015 making our job: Middle age job creation guide. Seoul, Korea: Korea Employment Information Service Publishing.

Kim, J. J., Park, B. S., \& Kwon, S. B. (2013). 2014 making our job: Youth age job creation guide. Seoul, Korea: Korea Employment Information Service Publishing.

Kim, J. M. (2001). Identification of job competencies in developing human resource: The case of a company which provides a preschool education program. Journal of Agricultural Extension \& Community Development, 8(2), 159177.

Kim, J. S., Lee, C. Y., Oh, H. M., \& Lee, H. J. (2013). A study on How to Activate Job Creation through Job Internship. Ministry of Employment and Labor Publishing. (MOEL)

Kim, J. S., Lee, K. H., Lee, W. J., \& Lee, C. Y. (2011). Sustainable Jobs through Youth Age Job Creation. Ministry of Employment and Labor Publishing. (MOEL)

Kim, J. W. (2019). A Study on the development and validation of an assessment tool for collegiate core competencies. Doctoral dissertation, Seoul University, Seoul, Korea.

Kim, R. \& S, H. D. (2017). University-level flipped classroom learner competency modeling. Journal of Educational Technology, 33(4), 1001-1024.

Korea National Statistical Office. (2019). May 2019 Additional Survey Results of Economically Active Population Survey. Korea National Statistical Office Publishing. (KOSTAT)

Korea National Statistical Office. (2008). Guidelines for using the Korean Standard Classification. Korea National Statistical Office Publishing. (KOSTAT)

Kwon, D. B. (2003). Comprehensive study on the concept change and theory of human resource development. Seoul, Korea: Wonmisa Publishing.

Le Deist, F. D., \& Winterton, J. (2005). What is competence. Human Resource Development International, 8(1), 27-46.

Lee, D. B. (2015). A study on the effect of supervisor's capability to relational achievement through trust based construction: Focusing on the food service franchise. Master's Thesis in Han-sung University, Seoul, Korea.

Lee, D. C. (2012). A study on relative importance and priority about core competencies of supervisors in foodservice franchise: Using AHP method. Doctoral dissertation, Sejong University, Seoul, Korea.

Lee, D. H. (2006). A study on the competency modeling and job competencies of a cabin Attendant. Doctoral dissertation, Kyung Hee University, Seoul, Korea.

Lee, H. M. (2009). Competency modeling \& competency evaluation. Seoul, Korea: Read-Read Publishing.

Lee, H. Y. \& Kim, J. S. (2018). A study on the entrepreneurial competency model in early-and late-Stage technology-based ventures, Asia-Pacific Journal of Business Venturing and Entrepreneurship, 13(4), 99-116.

Lee, J. A. \& Ahn, Y. S. (2018). Developing measurement tool of entrepreneurship for young entrepreneurs. Asia-Pacific Journal of Business Venturing and Entrepreneurship, 13(4), 
97-209.

Lee, J. A. \& Ahn, Y. S. (2019). Analyzing education needs for the development of entrepreneurship of university student. AsiaPacific Journal of Business Venturing and Entrepreneurship, 14(2), 73-82.

Lee, J. E. \& Kim, J. H. (2012). A study on the relationship between college students' essential skills and academic achievement. The Journal of Vocational Education Research, 31(2), 227-246.

Lee, J. W., Koo, M. M., \& Hwang, S. H. (2010). Research on activation plan for Youth Age Job Creation, Startup Intern Performance evaluation, Ministry of Employment and Labor Publishing. (MOEL)

Lee, S. S. (2014). A comparative diagnostic study for colleges through diagnostic studies of the core competency of university entrants: A case study of D women's university. The Korean Journal of Human Resource Development Quarterly, 16(4), 203-222.

Lee, Y. H. (2016). Development in core competence model of venture entrepreneurs. Doctor dissertation, Busan University, Busan, Korea.

Lim, D. W. (2018). A study on the relationship between marketsensing capability \& business performance: Moderating effect of marketing activity autonomy. Korean Management Consulting Review, 18(1), 141-153.

Lim, H. K. (2016). The impact of social capital on the degree of job creation motivation and intention. Master's Thesis in Kookmin University, Seoul, Korea.

Lim, J. H., Park, Y. H., \& Kim, M. H. (2015). A study on the development of competency model for university students. The Korean Journal of Human Resource Development Quarterly, 17(2), 125-153.

Lucia, A. D. \& Lepsinger, R. (1999). The Art and Science of Competency Models: Pinpointing Critical Success Factors in Organization. Jeong, J. C., Min, B. M. (2001). The Art and Science of Competency Models. Seoul, Korea: PSI Consulting Publishing.

Mansfield, R. S. (1996). Building competency models: Approaches for HR professionals. Human Resource Management, 35(1), 7-18.

McClelland, D. C. (1973). Testing for competence rather than for "Intelligence". American Psychologist, 28(1), 1-14.

McLagan, P. A. (1989). Models for HRD practice: The models. Training \& Development Journal, 43(9), 49-59.

Min, K. S., Moon, K. H., \& Hwang, M. K. (2017). Development of the competency model for Korea national police university students. The Policy Change Theory, 17(2), 57-86.

MK Ecomomy. The era of job creation oneself "if you tap it, it will open". Seoul, Korea. Tetrieved 29 September, 2009, from https://www.mk.co.kr/news/economy/view/2009/07/407060/.

Mirabile, R. J. (1997). Everything you wanted to know about competency modeling. Training \& Development, 51(8), 73-77.

Nam, S. R. (2015). The development of competency model for administrative staff at a national university and the analysis of their competency Level. Doctoral dissertation, Chung-buk University, Cheong-ju, Korea.
Noh, Y. S. \& Lee, S. S. (2013). A study on developing and validating the instrument for diagnosing the competency of university students: A case study of D women's university. The Korean Journal of Human Resource Development Quarterly, 15(3), 273-305.

Oh, J. H., Na, E. Y., \& Kang, B. D. (2016). Identifying latent profiles in K-CESA: Focused on $\mathrm{H}$ university. Journal of Korean HRD Research, 11(2), 31-56.

Park, B. S. (2018). A study of a teaching competency modeling at Korea polytechnics. Doctoral dissertation, Koreatech University, Seoul, Korea.

Park, C. O. \& Kim, S. M. (2004). The common factors of managerial competency in public enterprises. Korean Society and Public Administration, 15(1), 1-25.

Park, S. J. \& Song, Y. S. (2016). A study on development of a core competencies tool of university students according to specialized university. Journal of Vocational Education \& Training, 19(2), 79-107.

Park, W. S. (2002). Competence-oriented human resource management. Korea Labor Institute Publishing. (MOEL)

Park, Y. H., Jeon, J. S., \& Baik, J. M. (2014). Development of a competency model for the national university employee and educational needs analysis of the competencies. Journal of Competency Development \& Learning, 9(2), 51-67.

Parry, S. B. (1996). The quest for competencies. Training, 33(7), 48-56.

Shin, S. J. (2019). The effects of self-leadership on job satisfaction of chang-jik \& freelance workers: With the mediation effects of Innovativeness and risk-taking. Master's Thesis in Hanyang University, Seoul, Korea.

Son, S. H. (2016). A study on the development of key competency modeling and competency-based curriculums following teacher's professional life cycle. Doctoral dissertation, Incheon University, Incheon, Korea.

Sparrow, P. (1996). Linking competencies to pay: Too good be true? People Management, 2(23), 1-6.

Spencer, L. M., \& Spencer, S. S. (1993). Competence at work: Models for superior performance. Min, B. M., Park, D, K., Park, J. K., Jeong, J. C. (1997). Competence at Work. Seoul, Korea: PSI Consulting Publishing.

Seo, M. K. (2012). Franchisor's core competency and market orientation: Theirs relationship with environmental uncertainty, competitive advantage, and business performance. Doctoral dissertation, Sejong University, Seoul, Korea.

Yang, H. J. (2017). Development of university classroom model to improve the creative competence: Analysis of educational environment and delphi survey. Doctoral dissertation, Soongsil University, Seoul, Korea.

Yi, R. (2017). A study on the narratives of the successful experiences of creating new jobs. Journal of Narrative and Educational Research, 5(2), 5-26.

Yoon, H. S. \& Kim, C. K. (2019). A study on the effects of entrepreneurial passion on the intention of job creation through the exploration activity. Journal of Employment and Career, 9(3), 45-64. 


\section{Appendixes}

\section{Appendix 1-1: Job Creation Competency}

\begin{tabular}{|c|c|c|c|}
\hline Clusters & Competency & Definition & Behavior (K, S, A) / (K: Knowledge, S: Skill, A: Attitude) \\
\hline \multirow{17}{*}{$\begin{array}{c}\text { Individual } \\
\text { Value } \\
\text { Competency }\end{array}$} & \multirow{4}{*}{$\begin{array}{l}\text { Achievement } \\
\text { Orientation }\end{array}$} & \multirow{4}{*}{$\begin{array}{l}\text { Interest in doing well or } \\
\text { intent to challenge the } \\
\text { highest standard }\end{array}$} & Set challenging goals and act to achieve them $(A)$ \\
\hline & & & Prioritize goals to achieve them, and select targets based on priorities (S) \\
\hline & & & Invest resources and time $(\mathrm{A})$ \\
\hline & & & New things can be pursued to achieve the goal $(S, A)$ \\
\hline & \multirow{3}{*}{ Initiative } & \multirow{3}{*}{$\begin{array}{l}\text { Discover or create new } \\
\text { opportunities by } \\
\text { improving work } \\
\text { performance or } \\
\text { preventing problems }\end{array}$} & Do not give up even when faced with obstacles $(A)$ \\
\hline & & & Do much more than job demands $(A)$ \\
\hline & & & Predict and prepare for opportunities or problems that others have not caught (A) \\
\hline & \multirow{3}{*}{$\begin{array}{l}\text { Self- } \\
\text { Confidence }\end{array}$} & \multirow{3}{*}{$\begin{array}{l}\text { Belief in one's own ability } \\
\text { to do tasks }\end{array}$} & Be positive about your judgment or ability (A) \\
\hline & & & Have confidence in what one is doing $(A)$ \\
\hline & & & I have an attachment to my work, and I have an attitude to enjoy the situation (A) \\
\hline & \multirow{3}{*}{$\begin{array}{l}\text { Interpersonal } \\
\text { Understanding }\end{array}$} & \multirow{3}{*}{$\begin{array}{c}\text { The desire to understand } \\
\text { others } \\
\text { others }\end{array}$} & Grasp the other person's moods and feelings (S) \\
\hline & & & Listen to the other person's conversation $(\mathrm{S}, \mathrm{A})$ \\
\hline & & & $\begin{array}{c}\text { When a problem occurs, understand the other person's position and focus on } \\
\text { solving the problem (S) }\end{array}$ \\
\hline & \multirow{4}{*}{ Flexibility } & \multirow{4}{*}{$\begin{array}{l}\text { Ability to adapt to a } \\
\text { variety of situations, } \\
\text { individuals or groups, } \\
\text { and work efficiently }\end{array}$} & Accept the validity of the opposite view $(A)$ \\
\hline & & & Easily adapt and cope with variables (changes) that occur during work (S, A) \\
\hline & & & Can adapt the method to suit your situation or behavior (S) \\
\hline & & & Existing strategies can be drastically changed if the environment changes $(S, A)$ \\
\hline \multirow{17}{*}{$\begin{array}{c}\text { Job } \\
\text { Competency }\end{array}$} & \multirow{2}{*}{$\begin{array}{l}\text { Conceptual } \\
\text { Thinking }\end{array}$} & \multirow{2}{*}{$\begin{array}{l}\text { Ability to comprehend } \\
\text { fragmented information } \\
\text { to understand the entire } \\
\text { situation or problem }\end{array}$} & $\begin{array}{l}\text { It is possible to adapt existing knowledge or tools according to the current } \\
\text { situation (S) }\end{array}$ \\
\hline & & & Can apply items from other fields to my field $(\mathrm{K}, \mathrm{S})$ \\
\hline & \multirow{4}{*}{$\begin{array}{l}\text { Problem } \\
\text { Solving Ability }\end{array}$} & \multirow{4}{*}{$\begin{array}{l}\text { Ability to recognize and } \\
\text { solve problems correctly } \\
\text { through creative and } \\
\text { logical thinking when } \\
\text { problems arise }\end{array}$} & Can clearly define what the problem is $(\mathrm{K}, \mathrm{S})$ \\
\hline & & & Can explore various ways to solve the problem $(\mathrm{K}, \mathrm{S})$ \\
\hline & & & $\begin{array}{c}\text { Can verify that it is the right way to solve the problem by performing } \\
\text { the method you have sought }(\mathrm{K}, \mathrm{S})\end{array}$ \\
\hline & & & Try to solve the problem through various methods (A) \\
\hline & \multirow{4}{*}{$\begin{array}{l}\text { Analytical } \\
\text { Thinking }\end{array}$} & \multirow{4}{*}{$\begin{array}{l}\text { Comprehensive } \\
\text { understanding of the } \\
\text { situation and the ability to } \\
\text { grasp the implications } \\
\text { step by step and causally }\end{array}$} & Categorize and prioritize jobs based on their importance (S) \\
\hline & & & $\begin{array}{l}\text { Contents can be systematically divided into small units to deal } \\
\text { with complex tasks (S) }\end{array}$ \\
\hline & & & Provide solutions and find compromises when problems arise (S) \\
\hline & & & $\begin{array}{l}\text { It is possible to predict the future direction of technological development } \\
\text { in the field (S) }\end{array}$ \\
\hline & \multirow{4}{*}{$\begin{array}{l}\text { Market } \\
\text { Sensing }\end{array}$} & \multirow{4}{*}{$\begin{array}{l}\text { The process of } \\
\text { generalizing information } \\
\text { used for organizational } \\
\text { decision-making into } \\
\text { market knowledge }\end{array}$} & Be sensitive to trends $(\mathrm{K}, \mathrm{S})$ \\
\hline & & & Can figure out what customers want $(\mathrm{K}, \mathrm{S})$ \\
\hline & & & Can quickly grasp the competitors' movements $(K, S)$ \\
\hline & & & Can combine existing ideas with trends $(\mathrm{K}, \mathrm{S})$ \\
\hline & \multirow{3}{*}{$\begin{array}{l}\text { Information } \\
\text { Seeking }\end{array}$} & \multirow{3}{*}{$\begin{array}{l}\text { Ability to explore, collect } \\
\text { and screen information }\end{array}$} & Have the ability to search for information (S) \\
\hline & & & $\begin{array}{l}\text { When working on a project, you can search for the information you need to } \\
\text { find (S) }\end{array}$ \\
\hline & & & $\begin{array}{l}\text { When gathering information, it is possible to distinguish between necessary } \\
\text { and inappropriate information (S) }\end{array}$ \\
\hline
\end{tabular}


Appendix 1-2: Job Creation Competency

\begin{tabular}{|c|c|c|c|}
\hline Clusters & Competency & Definition & Behavior (K, S, A) / (K: Knowledge, S: Skill, A: Attitude) \\
\hline \multirow{10}{*}{$\begin{array}{l}\text { Leadership } \\
\text { Competency }\end{array}$} & \multirow{4}{*}{$\begin{array}{l}\text { Organizational } \\
\text { Commitment }\end{array}$} & \multirow{4}{*}{$\begin{array}{c}\text { The ability or } \\
\text { willingness to } \\
\text { promote the } \\
\text { achievement of an } \\
\text { organization's goals } \\
\text { by aligning the } \\
\text { individual's actions } \\
\text { with the } \\
\text { organization's } \\
\text { priorities and goals }\end{array}$} & Match my activities and priorities to organization's needs $(A)$ \\
\hline & & & Recognize the need for cooperation to achieve the organization's great goals (A) \\
\hline & & & Willing to help colleagues complete their mission (A) \\
\hline & & & $\begin{array}{l}\text { Be more responsive to the needs and goals of the organization than to my own personal } \\
\text { interests }(A)\end{array}$ \\
\hline & \multirow{3}{*}{$\begin{array}{l}\text { Teamwork and } \\
\text { Cooperation }\end{array}$} & \multirow{3}{*}{$\begin{array}{c}\text { Competencies that } \\
\text { include a sincere } \\
\text { intention to work } \\
\text { together }\end{array}$} & Express positive expectations for members $(\mathrm{A})$ \\
\hline & & & $\begin{array}{l}\text { Instilling confidence in members and encouraging them to feel that they are important (S, } \\
\mathrm{A} \text { ) }\end{array}$ \\
\hline & & & Can trust and cooperate with members $(\mathrm{A})$ \\
\hline & \multirow{3}{*}{$\begin{array}{c}\text { Team } \\
\text { Leadership }\end{array}$} & \multirow{3}{*}{$\begin{array}{c}\text { Competencies that } \\
\text { emerge from the } \\
\text { intention to assume } \\
\text { the leadership role }\end{array}$} & To distribute and lead work according to competency in order to carry out the project (S) \\
\hline & & & Encourage members of the organization to achieve their goals (S) \\
\hline & & & Leaders make decisions based on priorities (S) \\
\hline
\end{tabular}

